Movere Journal Vol 2 No. 1 Januari 2020 Hal 76-83

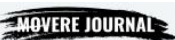

\title{
PENGARUH METODE BELAJAR TERHADAP MAHASISWA STIE TRI DHARMA NUSANTARA MAKASSAR
}

\author{
Ronny Ahmad Asirie ${ }^{(1)}$, Andi Abdul Razak Ishak ${ }^{(2)}$ \\ STIE Tri Dharma Nusantara Makassar
}

\begin{abstract}
Abstrak: Penelitian ini menganalisis apakah ada pengaruh metode belajar terhadap kelas eksperimen yang diperbandingkan dengan kelas kontrol pada mahasiswa/wi STIE Tri Dharma Nusantara Makassar. Jenis data yang digunakan adalah data kualitatif dan kuantitatif. Sumber data yang digunakan adalah primer dan sekunder . Dari hasil penelitian diperoleh nilai t hitung (equal variance not assumed) adalah 2.581 . Pada signifikansi $0.05: 2=0.025$ (uji 2 sisi) dengan derajad kebebasan (df), $\mathrm{n}$ -2 atau $90-2=88$, diperoleh $t$ tabel sebesar 1.9867 . Perbandingannya, nilai $t$ hitung $>\mathrm{t}$ tabel $(2.581>1.9867)$ dan signifikansi $<0.05(0.000<0.05)$, maka dengan demikian hipotesis disimpulkan bahwa ada perbedaan rata-rata perolehan nilai antara kelas M-S2A dan M-K2A.
\end{abstract}

Keyword : Metode Belajar, Perolehan Nilai

\section{PENDAHULAN}

Manusia adalah makhluk individu dan sebagai makhluk sosial. Sebagai makhluk sosial,manusia setiap saat berinteraksi kepada sesama lainnya. Secara kodrati, manusia akan selalu hidup bersama dalam berbagai bentuk komunikasi dan situasi. Salah satu interaksi yang dilakukan oleh manusia secara sengaja adalah pendidikan. Manusia sadar bahwa tanpa pendidikan perkembangan dan pertumbuhan potensi kemanusiaannya akan berjalan lamban dan tidak optimal. Fathurahman (2011:52) berpendapat " Interaksi pendidikan lebih jelas diamati pada lembaga pendidikan dimana adanya proses belajar-mengajar yang dilakukan oleh pendidik dalam hal ini adalah guru beserta murid sebagai yang terdidik. Proses pengajaran tidak semata-mata terpaku pada sistem transfer ilmu dan pengetahuan lalu menafikan hal lain dalam proses pembelajaran. Ada beberapa unsur-unsur yang penting, antara lain pembentukan akhlak,empati moral, kerakter, kejujuran, kedisiplinan dan toleransi . Menurut Charles F Silberman, pendidikan tidak sama pengertiannya dengan pengajaran . Pengajaran hanya menitik-beratkan pada usaha mengembangkan intelektualitas manusia, sedangkan pendidikan bertugas mengembangkan seluruh aspek kepribadian setiap manusia. Jadi, pengajaran merupakan bagian dari kegiatan pendidikan. Faturahman (2011:53). Berarti, salah satu tugas utama pendidik selain menyampaikan materi pengajaran adalah membimbing, sedikit berbeda dengan pengajar yang semata-mata hanya fokus pada materi pelajaran. Dalam membimbing peserta didik, 
diperlukan berbagai cara pendekatan agar setiap materi yang akan diutarakan/dijelaskan bisa tepat sasaran dan dapat difahami maupun diimplementasikan oleh peserta didik. Menurut Muhadjir Effendy (2018), Dalam menghadapi gencarnya revolusi industry 4.0 , dan Indonesia memiliki peluang sekaligus tantangan besar dalam menghadapi bonus demografi 2045. Setidaknya, 70 persen penduduk merupakan usia angkatan kerja yang menentukan masa depan bangsa. Penulis menilai tantangan besar tersebut haruslah diantisipasi sedini mungkin oleh pendidik, dan tetap mampu berdiri dipusat transformasi serta mengubah pola fikir dari sumber ilmu menjadi fasilitator, sebab revolusi industri bukan hanya pengembangan teknologi, melainkan soal kemajuan manusia berfikir. Teknologi hanya alat, tidak akan bermanfaat tanpa manusia yang kompeten dalam menggunakannya.

Berawal dari informasi dan gejolak fenomena yang mau atau tidak mau generasi kini dan akan datang harus menghadapinya, pendidik/pengajar dalam hal ini pula dituntut untuk memahami kerakteristik terdidik yang lebih kurang ada kesamaan dan homogen sesuai zaman atau angkatan . Selain dari pada itu, pemuktahiran materi ajar dan pendekatan pembelajaran tidak kalah penting sebagai jembatan antara pendidik/pengajar - materi dan peserta didik . Pendekatan pembelajaran tentunya memerlukan inisiatif dan inovatif berupa metode pembelajaran yang tidak lagi terpaku pada teknik one way communication. Sulistyowati Irianto (2019) menyatakan , metode pengajaran satu arah "dosen tidak pernah salah ", masih berlangsung. Sudah saatnya metode konvensional ini ditinggalkan, dan mengajak mahasiswa untuk off class, bertemu masyarakat dan realitas secara digital maupun empirik. Pendapat Purwanto (2014:20) "Pendidikan dapat dibatasi dalam pengertiannya yang sempit dan luas. Dalam arti sempit pendidikan adalah usaha sadar dan terencana untuk menolong anak didik menjadi matang kedewasaannya . Pendidikan dalam pengertian ini dilakukan oleh institusi formal sekolah . Disekolah materi disiapkan dalam bentuk kurikulum , strategi diorganisasikan dan evaluasi diselenggarakan untuk mengukur penguasaan materi yang direncanakan dan disampaikan menggunakan strategi tersebut

Dalam arti luas, semua manipulasi lingkungan yang diarahkan untuk mengadakan perubahan perilaku anak merupakan pendidikan. Semua perubahan kepribadian yang positif yang bukan karena kematangan merupakan hasil dari proses pendidikan. Penulis menganalisa untuk mempertemukan ketiga objek antara pendidik-materi dan peserta didik, penulis telah menyiapkan perangkat dalam mengelolah data-data yang berhubungan dengan fenomena tersebut. Memulainya dari mengubah model pembelajaran konvensional ke metode lainnya, untuk dan kepada salah satu dari dua populasi/kelas yang berbeda, satu kelas diperlakukan (eksperimen) dan kelas lainnya sebagai pembanding (kontrol). Lalu menyusun setiap data yang akan dikelola, dengan harapan , apakah dengan adanya perubahan pendekatan pembelajaran akan menghasilkan sesuatu yang positif berbeda atau sama saja dengan sebelum - sebelumnya . Metode pembelajaran yang diterapkan dalam penelitian ini adalah Problem Solving pada matakuliah Kewirausahaan semester $\mathrm{V}$ (lima) pendek tahun akademik 2018-2019.

\section{Hipotesis}

Berdasarkan pada rumusan (C) 2020 STIE TDN. All rights reserved 
masalah diatas , maka diajukan hipotesis yaitu : Apakah ada pengaruh metode belajar terhadap peraihan nilai akhir mahasiswa STIE Tri Dharma Nusantara Makassar.

\section{TELAAH LITERATUR DAN PENGEMBANGAN HIPOTESIS}

\section{Pengertian Metode Pemecahan Masalah (Problem Solving)}

Model pembelajaran merupakan istilah yang digunakan untuk mengambarkan penyelenggaraan proses belajar-mengajar dari awal sampai akhir. Dalam model pembelajaran sudah mencerminkan penerapan suatu pendekatan, metode, teknik atau taktik pembelajaran sekaligus. Menurut Mulyatiningsih (2012:237), metode pemecahan masalah (problem solving) sangat potensial untuk melatih peserta didik berfikir kreatif dalam menghadapi berbagai masalah. Didalam problem solving, peserta didik belajar sendiri untuk mengidentifikasi penyebab masalah dan alternatif untuk memecahkan masalah. Adapun langkah-langkah pembelajaran problem solving dapat dirancang sebagai berikut:

1. Guru menjelaskan tujuan pembelajaran

2. Guru memberikan kasus - kasus yang perlu dicari solusinya

3. Guru menjelaskan prosedur pemecahan masalah yang benar

4. Siswa mencari literatur yang mendukung untuk menyelesaikan kasus yang diberikan guru

5. Siswa menetapkan beberapa solusi yang dapat diambil untuk menyelesaikan kasus

6. Siswa memilih solusi dan menyusun cara pelaksanaannya

7. Siswa melaporkan tugas yang diberikan guru

Butir-butir pembelajaran yang telah disebutkan diatas, tidak akan menghadirkan jawaban dari eksperimen metode pembelajaran tanpa evaluasi penilaian yang akurat,adil dan netral, yang dilakukan oleh pendidik . Norman E Gronlund (1976:87) merumuskan pengertian evaluasi sebagai berikut: “ Evaluation... a systematic process of determining the extent to which instructional objectives are achieved by pupils ". (Evaluasi adalah suatu proses sistematis untuk menentukan atau membuat keputusan sampai sejauh mana tujuan-tujuan pengajaran telah dicapai oleh siswa) .

Pada semester ini, bahan atau data yang menjadi tolok-ukur bagi penulis adalah evaluasi formatifsumatif berupa kehadiran, interaksi kelas, tugas - tugas (essay), dan midfinal test . Uno,Hamzah B (2018:9899) menyatakan " Evaluasi formatif perlu dilakukan karena evaluasi ini adalah satu langkah dalam mengembangkan desain pembelajaran yang berfungsi untuk mengumpulkan data guna perbaikan pembelajaran. Adapun sumatif adalah pemberian nilai atas keefektifan dan efisiensi dalam kegiatan belajar - mengajar... dan diarahkan kepada pencapaian tujuan yang telah ditetapkan, yang diperlihatkan oleh unjuk kerja siswa" . Menurut Purwanto (2018:81) " Hasil belajar siswa bukan hanya sekedar angka yang dihadiahkan oleh guru untuk siswa atas kegiatan belajarnya. Hasil belajar merupakan ukuran kuantitatif yang mewakili kemampuan yang dimiliki oleh siswa. Adapun pengolahan data mentah menggunakan SPSS 22 (Statistical Product and Service Solution).

\section{METODE PENELITIAN}

\section{Lokasi dan Waktu Penelitian}

Pelaksanaan lokasi dan waktu penelitian di STIE Tri Dharma 
Nusantara Makassar. Selama 1(satu) semester tahun akademik 2018-2019

\section{Populasi dan Sampel}

Dalam penelitian ini yang menjadi populasi adalah dua kelas (MS2A , M-K2A) pada matakuliah Kewirausahaan, semester pendek V (lima), tahun akademik 2018/2019, yang berjumlah M-S2A $56+$ M-K2A $52=108$. Adapun penarikan sampel menggunakan rumus Nomogram Herry King. Sugiyono (2014:72)

Perhitungannya sebagai berikut: Populasi berjumlah 108, dengan kepercayaan sampel $95 \%$ dan tingkat kesalahan 5\%, maka jumlah sampel yang diambil $0.70 \times 108 \times 1.195=$ 90.342 dibulatkan menjadi 90 ,sehingga kelas eksperimen dan kelas kontrol terwakili sampel sebanyak @ 45 orang. Adapun tata cara penarikan sampel acak pada populasi kedua kelas , penulis menggunakan Generate Random Numbers in Excel. Menurut Hadi (2016:387) “ Agar teori kesimpulan - kesimpulan statistik mengandung kebenaran , maka sampel yang dipilih sebagai landasan penyimpulan haruslah mewakili atau representatif untuk populasinya. . Salah satu cara terbaik untuk memperoleh sampel semacam itu adalah teknik random sampling... (yang) menggunakan tabel bilangan random.

Tabel 1

\begin{tabular}{|l|l|l|l|}
\hline No.Urut & M-S2A & No.Urut & M-K2A \\
\hline 32 & 84 & 38 & 77 \\
\hline 50 & 79 & 34 & 80.5 \\
\hline 8 & 86 & 33 & 79 \\
\hline 30 & 84 & 17 & 80.5 \\
\hline 14 & 71 & 20 & 80.5 \\
\hline 4 & 86 & 35 & 80.5 \\
\hline 6 & 86 & 4 & 79 \\
\hline 28 & 81 & 23 & 77 \\
\hline
\end{tabular}

\begin{tabular}{|c|c|c|c|}
\hline 22 & 86 & 45 & 79 \\
\hline 13 & 79 & 42 & 80.5 \\
\hline 11 & 86 & 8 & 84 \\
\hline 52 & 79 & 18 & 80.5 \\
\hline 41 & 79 & 10 & 80.5 \\
\hline 44 & 86 & 50 & 77 \\
\hline 20 & 79 & 48 & 79 \\
\hline 23 & 79 & 6 & 84 \\
\hline 43 & 79 & 30 & 79 \\
\hline 34 & 81 & 28 & 81 \\
\hline 3 & 81 & 32 & 79 \\
\hline 35 & 77 & 27 & 79 \\
\hline 19 & 79 & 9 & 79 \\
\hline 42 & 86 & 47 & 79 \\
\hline 53 & 79 & 3 & 79 \\
\hline 33 & 79 & 31 & 79 \\
\hline 49 & 81 & 5 & 80.5 \\
\hline 51 & 71 & 12 & 77 \\
\hline 31 & 82.5 & 13 & 79 \\
\hline 24 & 79 & 21 & 77 \\
\hline 26 & 86 & 2 & 79 \\
\hline 10 & 84 & 29 & 79 \\
\hline 40 & 82.5 & 43 & 80.5 \\
\hline 45 & 71 & 7 & 77 \\
\hline 5 & 82.5 & 22 & 79 \\
\hline 12 & 86 & 37 & 80.5 \\
\hline 47 & 86 & 11 & 80.5 \\
\hline 17 & 86 & 52 & 77 \\
\hline 9 & 79 & 44 & 79 \\
\hline 15 & 84 & 24 & 80.5 \\
\hline 55 & 77 & 49 & 79 \\
\hline 46 & 80.5 & 26 & 79 \\
\hline 27 & 80.5 & 19 & 80.5 \\
\hline 48 & 82.5 & 39 & 77 \\
\hline 16 & 79 & 36 & 81 \\
\hline 18 & 79 & 16 & 80.5 \\
\hline 7 & 79 & 15 & 79 \\
\hline
\end{tabular}




\section{Metode Analisis}

Uji t dua sampel bebas (independent Sample T Test)

Uji ini akan membandingkan dua rata - rata dari dua grup yang tidak berhubungan satu dengan lainnya, dengan tujuan apakah kedua grup tersebut mempunyai rata - rata yang sama atau tidak .

Menurut Morrisan (2015:343) “ Uji-t dengan sampel kontrol adalah membandingkan dua kelompok sampel dimana salah satunya berfungsi sebagai sampel kontrol . Penelitian ini dilaksanakan dengan cara menguji dua variabel atau dua kelompok subjek yang mana satu kelompok menerima perlakuan tertentu sedangkan kelompok lainnya tidak menerima perlakuan, dan hanya berfungsi sebagai variabel kontrol . Dalam hal ini, kelas M-S2A sebagai eksperimen metode pembelajaran yang menggunakan metode problem solving , sedangkan kelas M-K2A adalah pembanding (kontrol)

\section{HASIL PENELITIAN DAN PEMBAHASAN}

Tabel 2

\section{Group Statistics}

\begin{tabular}{llrr|r|r} 
& M-K2A & $\mathrm{N}$ & \multicolumn{1}{c}{ Mean } & \multicolumn{1}{c}{ Std. Deviation } & Std. Error Mean \\
\hline $\begin{array}{l}\text { M-S2A } \\
\text { M-K2A }\end{array}$ & 1 & 45 & 81.089 & 4.0231 & .5997 \\
\cline { 2 - 6 } & 2 & 45 & 79.422 & 1.6059 & .2394 \\
\hline
\end{tabular}

\section{Output Group Statistik}

Rata-rata nilai tes kelas M-S2A berjumlah 45 data adalah 81.089 , dan rata-rata nilai akhir kelas M-K2A berjumlah 45 data adalah 79.422 . Standar deviasi nilai akhir untuk kelas
M-S2A berjumlah 4.0231, dan standar deviasi nilai akhir untuk kelas M-K2A berjumlah 1.6059. Adapun standard error mean kelas M-S2A berjumlah 0.5997 dan kelas M-K2A berjumlah 0.2394 .

Tabel 3

Independent Samples Test

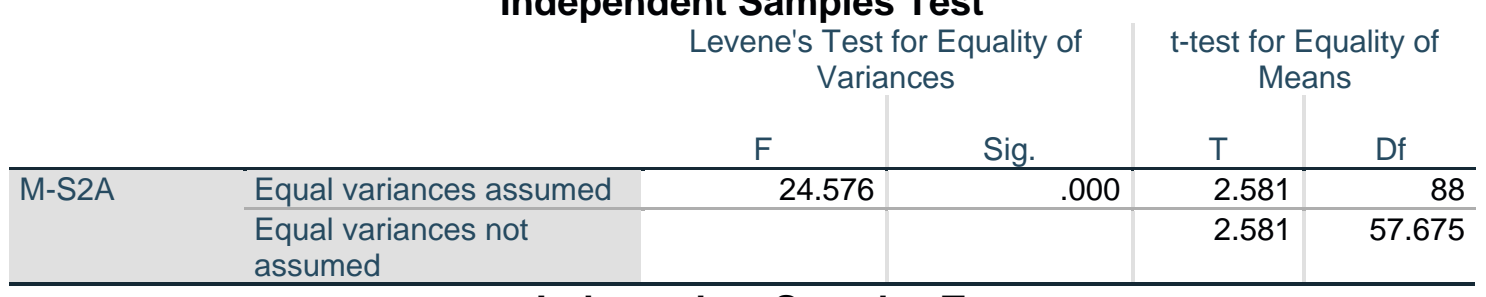

\begin{tabular}{|c|c|c|c|c|c|}
\hline \multicolumn{6}{|c|}{$\begin{array}{l}\text { Independent Samples Test } \\
\text { t-test for Equality of Means }\end{array}$} \\
\hline & & Sig. (2-tailed) & $\begin{array}{c}\text { Mean } \\
\text { Difference } \\
\end{array}$ & $\begin{array}{l}\text { Std. Error } \\
\text { Difference }\end{array}$ & $\begin{array}{l}95 \% \\
\text { Confidence } \\
\text { Interval of the } \\
\text { Difference } \\
\text { Lower }\end{array}$ \\
\hline$\overline{M-S 2 A}$ & Equal variances assumed & .012 & 1.6667 & .6457 & .3834 \\
\hline & $\begin{array}{l}\text { Equal variances not } \\
\text { assumed }\end{array}$ & .012 & 1.6667 & .6457 & .3739 \\
\hline & & dependent S & iples Test & \multicolumn{2}{|c|}{$\begin{array}{c}\text { t-test for Equality of Means } \\
\text { 95\% Confidence Interval of the } \\
\text { Difference } \\
\text { Upper }\end{array}$} \\
\hline
\end{tabular}




\section{Output Independent Sample Test}

Pengujian beda dua rata-rata menggunakan tingkat signifikansi 0.05, dan uji $F$ (homogenitas) digunakan untuk menentukan varian sama atau tidak sama yang dilanjutkan pada pengujian uji t.

Langkah-langkah uji $\mathrm{F}$ adalah sebagai berikut:

1. Merumuskan hipotesis.

a. Ho : Kelompok data dan peraihan nilai akhir antara kelas M-S2A dan M-K2A memiliki varian yang sama

b. Ha: Kelompok data dan peraihan nilai akhir antara kelas M-S2A dan M-K2A memiliki varian yang berbeda

2. Kriteria pengujian

a. Signifikansi >0.05, maka $\mathrm{H} 0$ diterima

b. Signifikansi $<0.05$, maka $\mathrm{H} 0$ ditolak

Signifikansi dari uji $\mathrm{F}$ sebesar 0.000 . karena nilai signifikansi $<0.05$ $(0.000<0.05)$, maka Ho ditolak dan disimpulkan kelompok data dan peraihan nilai akhir antara kelas $\mathrm{M}$ S2A dan M-K2A memiliki varian yang tidak sama. Oleh karena itu , uji t menggunakan Equal Variance Not Assumed.

Independent Samples T Test

1. Merumuskan hipotesis

Ho : Tidak ada perbedaan ratarata peraihan nilai akhir antara kelas M-S2A dan M-K2A

$\mathrm{Ha}$ : Ada perbedaan rata-rata peraihan nilai akhir antara kelas $\mathrm{M}$ S2A dan M-K2A

2. Hasil t hitung

Dari output didapat nilai $\mathrm{t}$ hitung (equal variance not assumed) adalah 2.581 . pada signifikansi 0.05 : $2=0.025$ (uji 2 sisi) dengan derajad kebebasan (df), $\mathrm{n}-2$ atau $90-2=88$ , diperoleh $\mathrm{t}$ tabel sebesar 1.9867

3. Pengujian

a. Jika $\mathrm{t}$ hitung $<\mathrm{t}$ tabel dan signifikansi $>0.05$, maka $\mathrm{H} 0$ diterima

b. Jika $\mathrm{t}$ hitung $>\mathrm{t}$ tabel dan signifikansi $<0.05$, maka $\mathrm{H} 0$ ditolak

4. Disimpulkan

Nilai $\mathrm{t}$ hitung $>\mathrm{t}$ tabel $(2.581>$

1.9867) dan signifikansi $<0.05$ ( 0.025 $<$ 0.05), maka $\mathrm{H} 0$ ditolak dan disimpulkan bahwa ada perbedaan rata-rata perolehan nilai akhir antara kelas M-S2A dan M-K2A.

\section{Tabel 4}

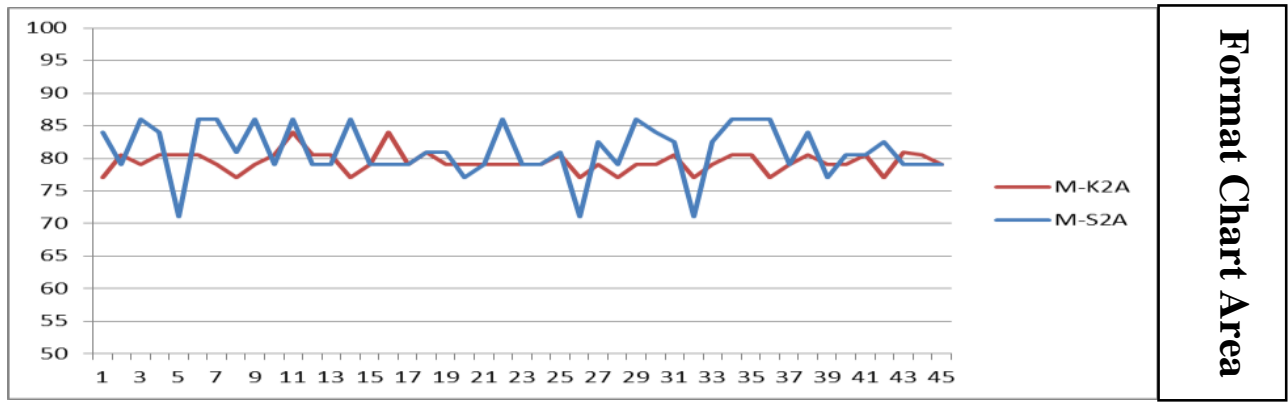

KESIMPULAN

Dari olah data pada penelitian ini diperoleh informasi yang penting, bahwa perubahan metode pembelajaran konvensional menjadi metode pemecahan masalah (problem 
solving) dapat meningkatkan minat dan pemahaman peserta didik hingga akhir semester tersebut pada mata perkuliahan kewirausahaan. Olah data yang diambil secara acak pada populasi menunjukkan kelas eksperimen yaitu M-S2A memiliki nilai rata - rata diatas daripada kelas M-K2A. Dari Format Chart Area terlihat hanya ada 3 (tiga) peserta didik dari kelas M-S2A yang mendapat nilai dibawah dari rata - rata sampel. Adapun selebihnya bersaing dan bahkan melebihi nilai- nilai yang diperoleh oleh kelas pembanding (kontrol), dalam hal ini adalah M-K2A yang grafiknya cenderung statis, dan khususnya sebahagian besar sampel T-TEST GROUPS=VAR02 ( 1 2 2 $)$

$/$ MISSING=ANALYSIS

/VARIABLES $=$ VAR0 1

/CRITERIA=CI (.95) . yang terpilih tidak memiliki lonjakanlonjakan yang melebihi grafik dari sampel kelas eksperimen.

\section{Saran}

Berdasarkan hasil dari analisis pada penelitian diperoleh jawaban bahwa metode belajar yang diterapkan oleh penulis mengalami peningkatan dari sisi minat belajar, pemahaman dan nilai akhir. Hal ini dapat pula diterapkan oleh pendidik/pengajar khususnya dosen. Atau , mencoba menggunakan metode pembelajaran lainnya yang sesuai dengan populasi serta kerakteristik peserta didik dan sebagai perbandingan pada metode konvensional.

\section{T-Test}

\begin{tabular}{|c|c|c|}
\hline \multirow{2}{*}{\multicolumn{2}{|c|}{ Output Created }} & \multirow[b]{2}{*}{ 05-OCT-2019 15:54:01 } \\
\hline & & \\
\hline \multicolumn{3}{|l|}{ Comments } \\
\hline \multirow[t]{5}{*}{ Input } & Active Dataset & DataSet0 \\
\hline & Filter & $<$ none $>$ \\
\hline & Weight & $<$ none $>$ \\
\hline & Split File & $<$ none $>$ \\
\hline & $\begin{array}{l}\mathrm{N} \text { of Rows in Working } \\
\text { Data File }\end{array}$ & 90 \\
\hline \multirow[t]{2}{*}{ Missing Value Handling } & Definition of Missing & $\begin{array}{l}\text { User defined missing values are } \\
\text { treated as missing. }\end{array}$ \\
\hline & Cases Used & $\begin{array}{l}\text { Statistics for each analysis are based } \\
\text { on the cases with no missing or out-of- } \\
\text { range data for any variable in the } \\
\text { analysis. }\end{array}$ \\
\hline Syntax & & $\begin{array}{l}\text { T-TEST GROUPS=VAR02(1 2) } \\
\text { /MISSING=ANALYSIS } \\
\text { /VARIABLES=VAR01 } \\
\text { /CRITERIA=CI(.95). }\end{array}$ \\
\hline \multirow[t]{2}{*}{ Resources } & Processor Time & 00:00:00.05 \\
\hline & Elapsed Time & 00:00:00.09 \\
\hline
\end{tabular}

\section{DAFTAR PUSTAKA}

Effendy, M. 2018. Pemerataan Mutu Menjadi Prioritas. Kompas PP 11

Fathurahman, P. 2011. Metode
Penelitian

Pendidikan.

Bandung. Penerbit Pustaka Setia.

Gronlund, N.E. 1974. Improving Marking and Reporting in Classroom Instruction, Macmillan Publishing Co.,Inc., New York 
Hadi, S. 2016. Metodologi Riset. Yogyakarta. Penerbit Pustaka Pelajar

Mulyatiningsih,E. 2012. Metode Penelitian Terapan Bidang Pendidikan. Bandung. Penerbit Alfabeta

Irianto,S.(2019). Pendidikan Tinggi Tersembunyi. Kompas pp 6

Morrisan. 2015. Metode Penelitian Survey. Jakarta. Penerbit PT.Fajar Interpratama Mandiri

Purwanto. 2014. Evaluasi Hasil Belajar . Yogyakarta. Penerbit Pustaka Pelajar

Ngalim,P.M. 2013. Evaluasi Pengajaran,.Bandung. Penerbit PT.Remaja Rosdakarya

Sugiyono. 2014. Statistika Untuk Penelitian . Bandung. Penerbit Alfabeta

Uno,Hamzah $\quad$ B. 2018 . Model Pembelajaran. Jakarta. Penerbit Bumi Aksara 